\title{
The Mechanism of Folate
}

\section{Transport in Rabbit Reticulocytes}

\author{
WIILIAM F. Bobzien III and I. David Goldman \\ From the Department of Medicine, University of North Carolina School of \\ Medicine, Chapel Hill, North Carolina 27514
}

A B S T R A C T Folate transport in phenylhydrazine-induced rabbit reticulocytes was studied with the nonmetabolized folate-analog, methotrexate. The time-course of methotrexate uptake into a mixed population of reticulocytes and mature erythrocytes is a two-component process consisting of a small, but rapid, initial uptake phase followed by a much slower uptake component which remains essentially constant over the period of observation. The velocity of the latter uptake component is directly proportional to the per cent reticulocytes and appears to represent a unidirectional influx of methotrexate into these cells. Uptake of methotrexate into reticulocytes was found to have the following characteristics: (a) temperature sensitivity, $Q_{10}$ of 4 ; (b) uptake velocity as a function of the extracellular methotrexate concentration approximated Michaelis-Menten kinetics with a maximum transport velocity of 48 pmoles/ min per $g$ dry wt; the extracellular methotrexate level at which the uptake velocity was one-half maximum was $1.4 \mu_{\mathrm{M}}$; (c) 5-formyltetrahydrofolate markedly inhibited methotrexate uptake but pteroylglutamic acid inhibition was weak; $(d)$ uptake was stimulated in cells preincubated with 5-formyltetrahydrofolate, indicative of heteroexchange diffusion; (e) uptake was independent of extracellular sodium but was inhibited by anions including nitrate, phosphate, and glucose-6-phosphate; $(f)$ uptake was enhanced by azide plus iodoacetate.

These data indicate that folate transport in rabbit reticulocytes is mediated by a carrier mechanism which disappears with reticulocyte maturation. The mechanism of folate transport in rabbit reticulocytes is qualitatively similar to tumor cells previously studied; both appear to have an energy-dependent mechanism limiting folate uptake, and influx in both is inhibited by structurally unrelated inorganic and organic anions. These studies suggest that circulating pteroylglutamic acid is of little importance in meeting the folate requirements of folate-

Received for publication 11 November 1971 and in revised form 22 February 1972. dependent tissues and raise the possibility that clinical conditions associated with alterations in the anionic composition of the blood may be accompanied by impaired utilization of the folates.

\section{INTRODUCTION}

Previous studies from this laboratory have characterized a carrier mechanism for the transport of methotrexate, MTX, ${ }^{1}$ and the naturally occurring folates across the cell membrane of Ehrlich ascites and L1210 murine leukemia cells (1-6). MTX has served as a model substrate (5) for the study of the transport properties of this group of compounds because: ( $a$ ) its uptake is rapid; (b) unlike the naturally ocurring folates, MTX is not metabolized by these cell systems; (c) MTX is readily available as the tritiated isotope at high specific activity, with excellent purity after column chromatography, and with satisfactory stability; $(d)$ the tight intracellular binding of MTX to dihydrofolate reductase permits very accurate measurements of unidirectional influx rates. This transport mechanism is unusual in that although these cells can maintain intracellular MTX at a higher electrochemical-potential relative to its extracellular species (1), metabolic inhibitors do not reduce the intracellular MTX level, but rather lead to an increase in the unidirectional influx of MTX, a fall in the unidirectional efflux rate, and a large rise in the apparent intracellular electrochemical-potential (3). Furthermore, transport of MTX is not sodium dependent; rather, both the unidirectional influx and the intracellular electrochemicalpotential of MTX are reduced by the extracellular presence of a variety of structurally unrelated inorganic and organic anions $(5,6)$.

Because of the major importance of the folate com-

1 Abbreviations used in this paper: folic acid, pteroylglutamic acid; 5-formylTHF, 5-formyl-5,6,7,8-tetrahydropteroyl-L-glutamic acid; MTX, methotrexate (4-amino- $N^{10}$ methylpteroylglutamic acid). 
pounds in cellular biosynthetic processes (7) and in view of the unusual properties of the folate transport system in the tumor cells studied, it was of interest to determine whether this folate transport mechanism is unique to tumor cells or is a more generalized phenomenon of folate transport in mammalian tissues. To explore this further, studies were undertaken with rabbit erythrocytes, and the results of these experiments are the subject of this report.

\section{METHODS}

Preparation of cells. Erythrocytes were obtained from New Zealand white rabbits weighing 4-7 lb. Reticulocytosis was induced by the subcutaneous injection on 2-3 successive days of $50 \mathrm{mg}$ of phenylhydrazine in a $2.5 \%$ aqueous solution adjusted to $\mathrm{pH} 7$ with $\mathrm{NaOH}$. This was repeated after a delay of 5 days to sustain the reticulocytosis. To prevent folate deficiency with the chronic administration of this agent, animals were given $15 \mathrm{mg}$ of folic acid subcutaneously with each cycle of exposure to phenylhydrazine. By this technique, reticulocyte levels approaching $100 \%$ could be achieved. In some experiments reticulocytosis was induced by bleeding (See Results section, "The relationship between MTX uptake and reticulocyte level"), but because much higher reticulocyte levels could be achieved with phenylhydrazine, the latter technique was utilized for all other studies.

$48 \mathrm{hr}$ after the last injection of phenylhydrazine, blood was collected from a marginal ear vein in $25 \mathrm{vol}$ of $0^{\circ} \mathrm{C}$ buffer (see below); under these conditions coagulation did not occur. The red cell fraction was collected by centrifugation in a $40 \mathrm{ml}$ round bottom tube at $1000 \mathrm{~g}$ for $2 \mathrm{~min}$, the supernatant fluid was aspirated, and the cell pellet washed twice with $0^{\circ} \mathrm{C}$ buffer. This procedure resulted in the isolation of a red cell pellet which contained less than $50 \%$ of the leukocytes and less than $10 \%$ of the platelets originally present. Further removal of more than $90 \%$ of the leukocytes was accomplished in some experiments by resuspending the cells into buffer containing 3\% dextran (average mol wt $=200,000$ ). After sedimentation for 1 $\mathrm{hr}$, the supernatant fluid was aspirated, the cell fraction separated by centrifugation, and the dextran removed by two washes with $0^{\circ} \mathrm{C}$ buffer. The cell pellets were maintained at $0^{\circ} \mathrm{C}$ until the time of experimentation.

Buffer and incubation procedures. The buffer employed in these studies has the following composition: $\mathrm{NaCl}, 136$ $\mathrm{mm} ; \mathrm{KCl}, 4.5 \mathrm{~mm}$; $\mathrm{NaHCO}_{3}, 16 \mathrm{~mm} ; \mathrm{KH}_{2} \mathrm{PO}_{4}, 1.1 \mathrm{~mm}$; $\mathrm{MgCl}_{2}, 1.9 \mathrm{~mm}$; and $\mathrm{CaCl}, 1.0 \mathrm{~mm}$. The $\mathrm{pH}$ was adjusted to 7.4 in an atmosphere of $95 \% \quad \mathrm{O}_{2}-5 \% \quad \mathrm{CO}_{2}$. The final buffer osmolality was $290 \mathrm{mOsm} / \mathrm{liter}$. In some experiments, sodium, chloride, or both ions were replaced by other solutes; this replacement was isosmotic. Erythrocyte cytocrits were less than $10 \%$. Under these conditions the $\mathrm{pH}$ did not change more than $0.2 \mathrm{U}$ over a $1 \mathrm{hr}$ experiment. Hemolysis was less than $3 \%$ after $1 \frac{1}{2} \mathrm{hr}$ under all experimental conditions.

Measurement of MTX uptake and efflux. The $40 \mathrm{ml}$ centrifuge tube containing the red blood cell pellet at $0^{\circ} \mathrm{C}$ was warmed by immersion in a $37^{\circ} \mathrm{C}$ water bath after which the cell pellet was dispersed by the addition of the appropriate buffer containing $\mathrm{MTX}-{ }^{8} \mathrm{H}$ at $37^{\circ} \mathrm{C}$. After a brief vortex mix, the suspension was added to flasks aerated with warmed and humidified $95 \% \mathrm{O}_{2}-5 \% \mathrm{CO}_{2}$, and stirred continuously with a teflon paddle as previously described (1). Timed samples of the cell suspension were removed and injected into 10 vol of $0^{\circ} \mathrm{C} 0.85 \%$ saline (to be referred to as $\mathrm{NaCl}$ solution); this procedure halts the uptake of MTX. Exchangeable MTX was determined in cells first preincubated with $M T X-{ }^{3} \mathrm{H}$, then washed free of MTX with $0^{\circ} \mathrm{C}$ buffer, and finally resuspended into a large volume of this buffer at $37^{\circ} \mathrm{C}$. The cell suspension was sampled as described above.

Analytical procedures. The analytical procedures have been described in detail previously $(1,3,4)$. Briefly, erythrocytes were separated by centrifugation at $2000 \mathrm{~g}$ for 1 min and washed twice with $0^{\circ} \mathrm{C} \mathrm{NaCl}$ solution. After the last wash, the supernatant fluid was thoroughly aspirated and the cell pellet drawn into the tip of a pasteur pipet and extruded onto a polyethylene tare. The pellets were dried, separated from their tares, and weighed directly on a Cahn G-2 electrobalance (Cahn Instruments, Paramount, Calif.) The pellets were then transferred to scintillation vials which were positioned at a $45^{\circ}$ angle in specially designed racks so that the subsequent addition of $100 \mu \mathrm{l}$ of $1 \mathrm{~N} \mathrm{KOH}$ would completely encompass the cell material. After a $1 \mathrm{hr}$ digestion at $70^{\circ} \mathrm{C}$, the vials were cooled and the solution decolorized by the addition of $100 \mu \mathrm{l}$ of $30 \%$ $\mathrm{H}_{2} \mathrm{O}_{2}$ to minimize color quenching. After addition of $15 \mathrm{ml}$ of the scintillation cocktail, ${ }^{2}$ there was marked chemiluminescence which fell to background within $24-48 \mathrm{hr}$, after which the samples were counted on a liquid scintillation spectrometer.

Intracellular volume and chloride concentration were determined on unwashed cell pellets employing inulin ${ }^{-14} \mathrm{C}$ as an extracellular marker as previously described in detail (1). For determination of inulin- ${ }^{14} \mathrm{C}$, a $75 \mu$ portion of the $\mathrm{KOH}$ digest was transferred to a scintillation vial and decolorized with an equal volume of $30 \% \mathrm{H}_{2} \mathrm{O}_{2}$ after which $75 \mu 1$ of $12 \mathrm{~N} \mathrm{HCl}$ was added and the solution incubated at $70^{\circ} \mathrm{C}$ for $45 \mathrm{~min}$. The latter digestion results in the hydrolysis of inulin to the more soluble fructose (8). This procedure circumvents the technical difficulties that arise from the poor solubility of inulin which results in its precipitation in the scintillation cocktail with a subsequent rapid falloff in counting efficiency. Chloride was determined from the $\mathrm{KOH}$ digest on a Buchler-Cotlove chloridimeter (Buchler Instruments, Inc., Fort Lee, N. J.).

Chemicals. MTX- ${ }^{3} \mathrm{H}$ obtained from Amersham/Searle Corp. (Arlington Heights, Ill.) and nonlabeled MTX obtained from American Cyanamid Co., Lederle Laboratories Div. (Pearl River, N. Y.) were purified on a diethylaminoethyl (DEAE)-cellulose column as previously described (1). 5-formylTHF (racemic) was obtained from Lederle Laboratories; concentrations noted indicate the active Ldiasterioisomer. Inulin $-{ }^{14} \mathrm{C}$ was obtained from Amersham/ Searle. Sodium azide and sodium iodoacetate were obtained from Fisher Scientific Company (Pittsburgh, Pa.) and phenylhydrazine hydrochloride was obtained from Sigma Chemical Company (St. Louis, Mo.).

Identification of accumulated material. The possibility of metabolism of $\mathrm{MTX}^{-{ }^{3} \mathrm{H}}$ by rabbit reticulocytes was evaluated. Erythrocyte suspensions composed of $>60 \%$ reticulocytes were incubated with $1 \mu \mathrm{M}$ MTX- ${ }^{8} \mathrm{H}$ at $37^{\circ} \mathrm{C}$ for $1 \frac{1}{2} \mathrm{hr}$, then washed with $0^{\circ} \mathrm{C}$ buffer and resuspended into $0^{\circ} \mathrm{C}-0.1$ м $\mathrm{NH}_{4} \mathrm{HCO}_{3}$. After disruption by sonic oscillation, the sonicate was centrifuged at $11,000 \mathrm{~g}$ to remove

$2700 \mathrm{ml}$ of toluene, $300 \mathrm{ml}$ of methanol, $3 \mathrm{~g}$ of 2,5 -diphenyloxazole, $37.5 \mathrm{mg}$ of $p$-bis [2-(5-phenyloxazolyl)] benzene. 


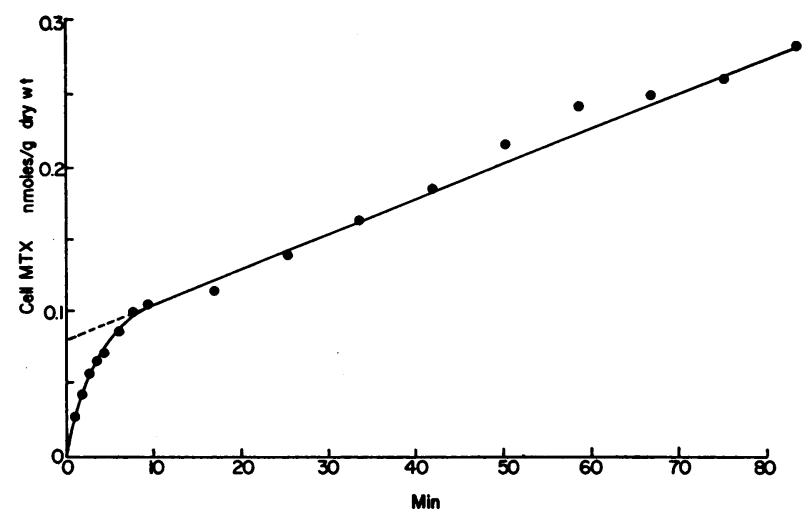

FIgURE 1 The time-course of MTX uptake into rabbit erythrocytes. The extracellular MTX level was $1 \mu \mathrm{M}$. The reticulocyte level was $2 \%$. The interrupted line represents an extrapolation of the linear second uptake component, the significance of which is considered further in the Discussion.

the particulate matter which contained negligible radioactivity. The supernatant fluid was diluted with nonlabeled MTX and fractionated on a DEAE-cellulose column as previously described (1). In three such experiments more than $94 \%$ of the radioactivity added to the column was recovered in the MTX peak. No other peak of radioactivity was noted.

Statistical methods. All linear regression analyses reported as well as linear graphs were determined by the method of least squares. The standard deviation of the slopes and ordinate intercepts of all lines were calculated as described elsewhere (9). All data are expressed as mean $\pm S D$. Differences between the slopes or ordinate intercepts of all lines were analyzed by Student's test.

\section{RESULTS}

Time-course of MTX uptake and efflux. Fig. 1 illustrates the time-course of MTX uptake in a cell sus-

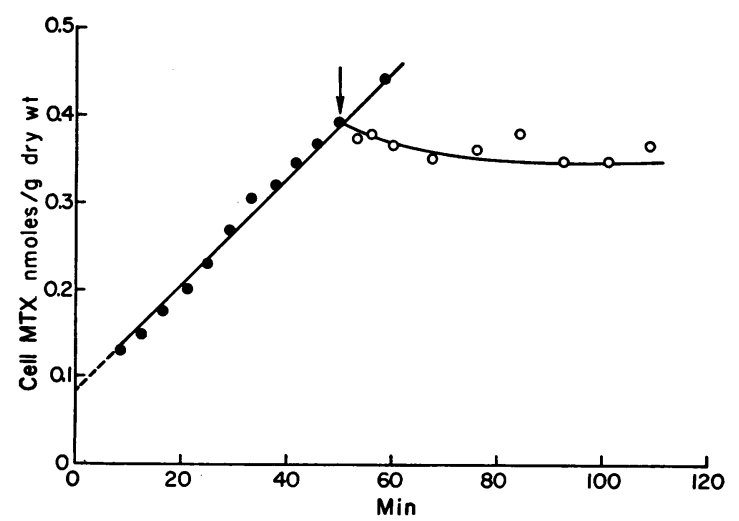

FIgURE 2 Exchangeability of intracellular MTX. Cells were incubated for $50 \mathrm{~min}$ with MTX at an extracellular concentration of $0.33 \mu \mathrm{M}$. At the arrow a portion of the cell suspension was removed, washed free of MTX, and resuspended into a large volume of MTX-free buffer at $37^{\circ} \mathrm{C}$. The time-course of eiflux was monitored. The reticulocyte level was $69 \%$. pension composed of approximately $2 \%$ reticulocytes at an extracellular MTX level of $1 \mu_{\mathrm{M}}$. Uptake is a two-component process. There is an initial rapid uptake phase after which the rate falls to become essentially constant for at least $1 \mathrm{hr}$. The major portion of MTX taken up by the cells under these conditions appears to be nonexchangeable as illustrated in Fig. 2 . Here, cells preloaded with MTX were separated by centrifugation and resuspended into a large volume of MTX-free buffer; only a small quantity of MTX was exchangeable. The two-component uptake process is not related to the presence of other contaminating blood cell types in the suspension. Platelets are virtually completely removed by the routine preparative procedures, and while $50 \%$ of the leukocytes remain under usual conditions, further removal of more than $90 \%$ of these cells by dextran sedimentation does not alter the uptake sequence.

The measurement of initial rates in the time-course of uptake is technically difficult due to low intracellular radioactivity. In view of this and the observation that the first uptake component is a very small part of the total MTX taken up over a long time interval (see reticulocyte uptake, Fig. 3), the data to be presented will be primarily concerned with the characterization of the properties of the more important second uptake component.

The relationship between $M T X$ uptake and reticulocyte level. Fig. 3 compares the time-course of MTX uptake at reticulocyte levels of $1.5 \%$ and near $100 \%$. When the reticulocyte level is high, the second component uptake velocity is markedly increased. Fig. 4 describes the second component uptake velocity as a function of the per cent reticulocytes. These parameters are linearly related $(r=0.98)$ with the intercept passing through the ordinate axis at a point not significantly

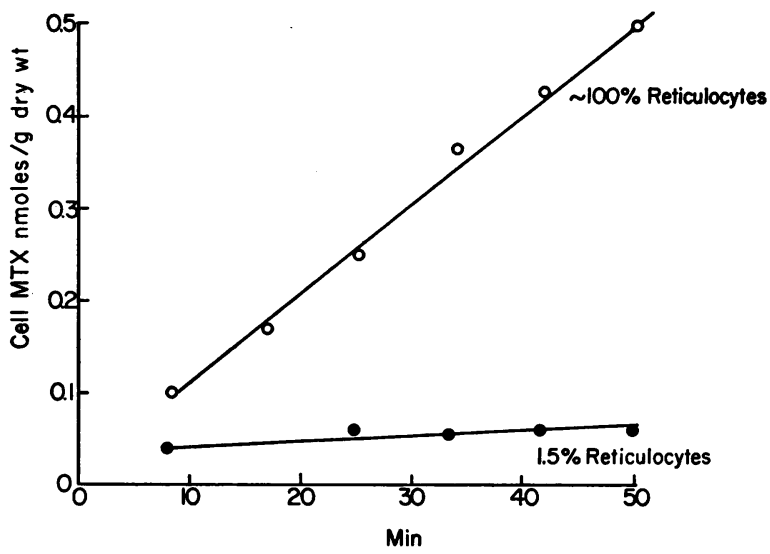

Figure 3 The time-course of MTX uptake in cell suspensions of $1.5 \%$ and near $100 \%$ reticulocytes. The extracellular MTX level was $0.5 \mu \mathrm{M}$. 
different from zero. Since the second component uptake velocity is proportional to the percentage of reticulocytes, and this rate falls towards zero as the per cent reticulocytes approaches zero, this uptake component is attributed solely to transport of MTX into reticulocytes; the contribution of mature erythrocytes to this component of uptake must be insignificant. A twocomponent uptake sequence was observed in reticulocyte-rich suspensions whether reticulocytes were generated by bleeding or phenylhydrazine and the velocity of the second uptake component was similar at a given reticulocyte level irrespective of the method by which reticulocytosis was induced.

Uptake kinetics for MTX. The relationship between the extracellular MTX level and the second component uptake velocity was evaluated in a series of experiments performed on different days with cell suspensions of different reticulocyte levels. Because the second uptake component was directly proportional to the per cent reticulocytes, variability in this parameter was eliminated by normalizing all velocities to the value that would be expected for a reticulocyte level of $100 \%$. For these studies, uptake was confined to the linear phase and cytocrits were adjusted so that alterations in the extracellular MTX level due to cellular uptake were negligible. Fig. 5 is a double-reciprocal plot of this data. The linear correlation coefficient is 0.88 with a positive ordinate intercept which differs significantly from zero $(P<0.001)$. These data suggest that the second uptake component for MTX deviates from a first order process and approximates Michaelis-Menten kinetics. The estimated maximum uptake velocity, $\mathrm{V}_{\max }$, is $0.048 \mathrm{nmoles} / \mathrm{min}$ per $\mathrm{g}$ dry wt. The uptake $\mathrm{K}_{\mathrm{t}}$, the extracellular MTX level at which the uptake rate is

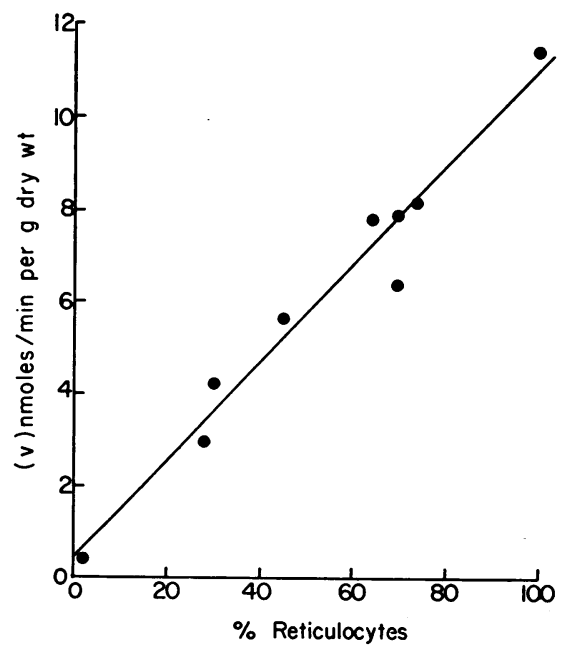

Figure 4 The relationship between the second component uptake velocity (V) and the per cent reticulocytes.

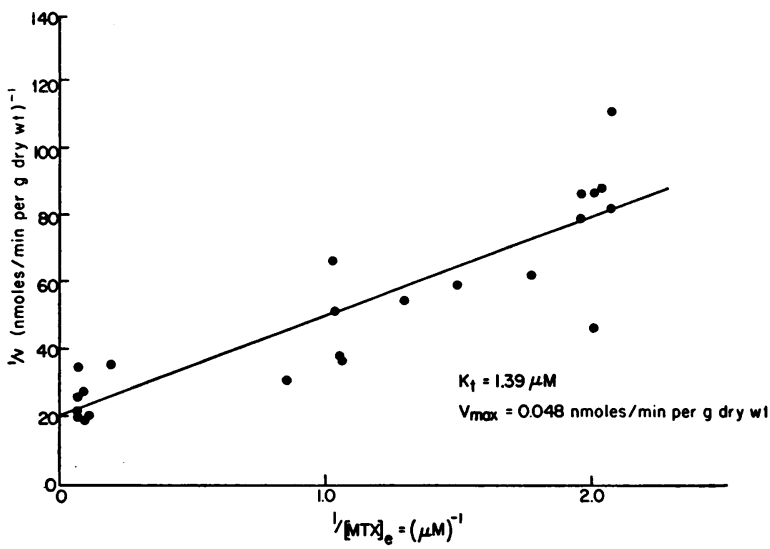

FIGURE 5 A double reciprocal plot of the relationship between the velocity of the second uptake component and the extracellular MTX level, (MTX). All data were normalized to $100 \%$ reticulocytes.

$\frac{1}{2} \mathrm{~V}_{\max }$, is $1.4 \mu_{\mathrm{M}}$. It is of interest that whereas the uptake $\mathrm{K}_{\mathbf{t}}$ for reticulocytes is within the same order of magnitude as L1210 tumor cells, the $\mathrm{V}_{\max }$ is two orders of magnitude slower (1).

Other characteristics of MTX uptake: temperature sensitivity and inhibition by folic acid and 5-formyl$T H F$. The average $Q_{10}$ for the second component uptake velocity between 27 and $37^{\circ} \mathrm{C}$ is 4 . The presence of folic acid or 5-formylTHF in the extracellular compartment inhibits the uptake of MTX (Fig. 6); however, the degree of inhibition by these compounds is quite different. While 5-formylTHF at a level equimolar to MTX produced an $80 \%$ reduction in the second component uptake rate, six times the concentration of folic acid reduced this rate by only $28 \%$.

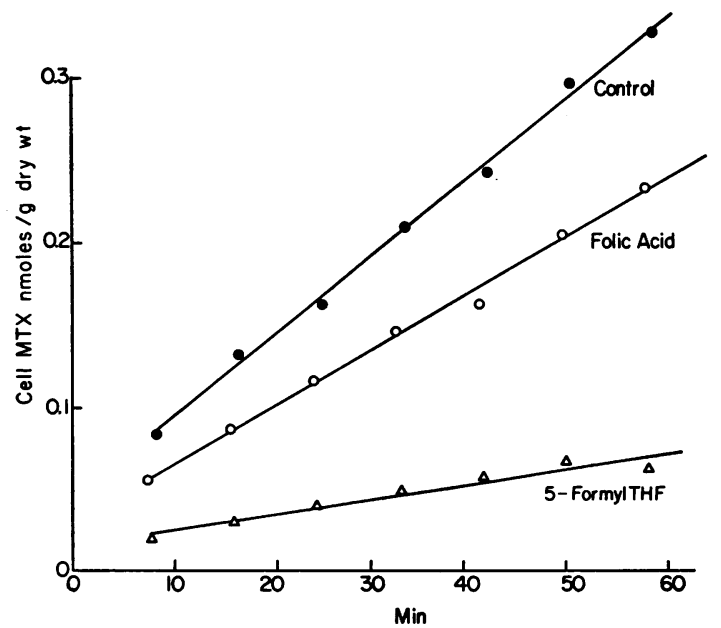

FIGURE 6 The effect of folic acid or 5-formylTHF on the uptake of MTX. Cells were incubated with $15 \mu \mathrm{M}$ MTX as a control or in the presence of $100 \mu \mathrm{M}$ folic acid or $15 \mu \mathrm{M} 5$-formylTHF. The reticulocyte level was $30 \%$. 


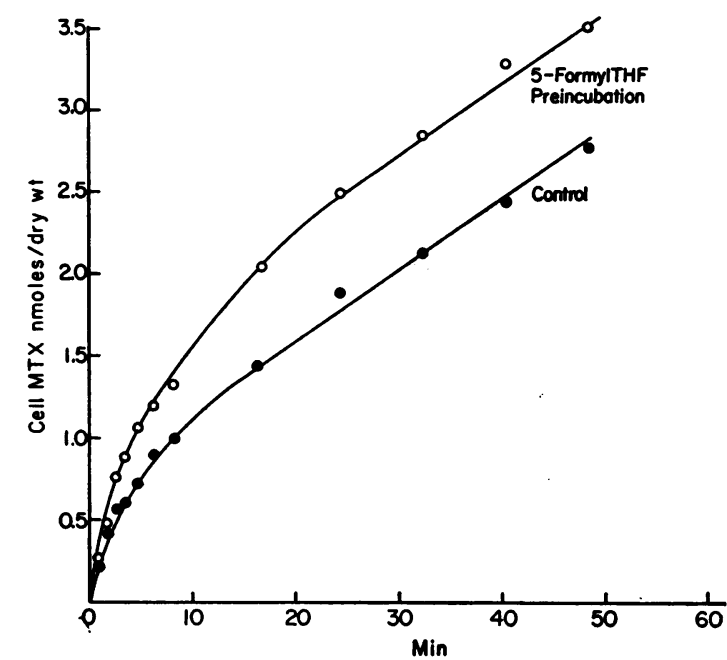

Figure 7 Heteroexchange diffusion. Cells were incubated as a control or in the presence of $0.45 \mathrm{~mm}$ 5-formylTHF. After $60 \mathrm{~min}$ the cell fractions were separated by centrifugation and washed with $0^{\circ} \mathrm{C}$ folate-free buffer. After prewarming the cell pellet for $1 \mathrm{~min}$, the cells were resuspended at time zero into $37^{\circ} \mathrm{C}$ buffer containing tritiated MTX at a level of $15 \mu \mathrm{M}$. The reticulocyte level was $64 \%$.

Heteroexchange diffusion. Fig. 7 illustrates the results of an experiment in which MTX uptake was measured in control cells and cells preincubated with 5-formylTHF. There was a small rise in the initial uptake rate in the cells preincubated with 5 -formylTHF, but the major change was related to a prolongation of the initial uptake rate in these cells with enhanced net uptake for about $15 \mathrm{~min}$ after which the second component uptake velocities for the control and preincubated cells became identical.

The effect of metabolic inhibitors on MTX uptake. Since intracellular MTX does not achieve a steady state in these experiments, and because the analysis of free intracellular MTX pools may be complicated by the presence of two intracellular compartments, both of which appear to contain tight binding sites for MTX (see Discussion), the electrochemical-potential difference for MTX across the cell membrane under steadystate conditions could not be determined, thus complicating an analysis of the energetics of this transport system. However, the effect of metabolic inhibitors on MTX uptake was examined. The closed points of Fig. 8 illustrate part of an experiment in which cells were simultaneously exposed to MTX- ${ }^{8} \mathrm{H}$ in the presence or absence of $10 \mathrm{~mm}$ azide and $1 \mathrm{~mm}$ iodoacetate. There was a marked increase in the second component uptake velocity in the cells exposed to metabolic inhibitors.

To determine whether alterations in cell volume or membrane potential contribute to the stimulation of
MTX uptake observed in the presence of azide and iodoacetate, cell volume and chloride distribution ratios (the ratio of the concentration of chloride in the intracellular to extracellular water) were determined over a $1 \mathrm{hr}$ interval. Unlike the tumor cell systems previously studied (1), the chloride distribution ratio for erythrocytes is a more reliable parameter for the estimation of the transmembrane potential difference (10). Table I is a composite of five experiments and indicates that cell volume, as estimated from the ratio of the intracellular water to dry weight, is the same in both groups and remains constant over the period of observation. Nor is there a significant difference between the chloride distribution ratios of the control cells and those exposed to the metabolic poisons, although in both groups there is a small parallel rise with time. Further, significant changes do not occur in other cell parameters such as the ratio of dry to wet weight, or the ratio of the extracellular water to wet weight (inulin space).

Although the level of free intracellular MTX increases in the presence of metabolic poisons, a steady state is not achieved nor is an intracellular level for free MTX approached that would be expected if this compound were passively distributed across the cell

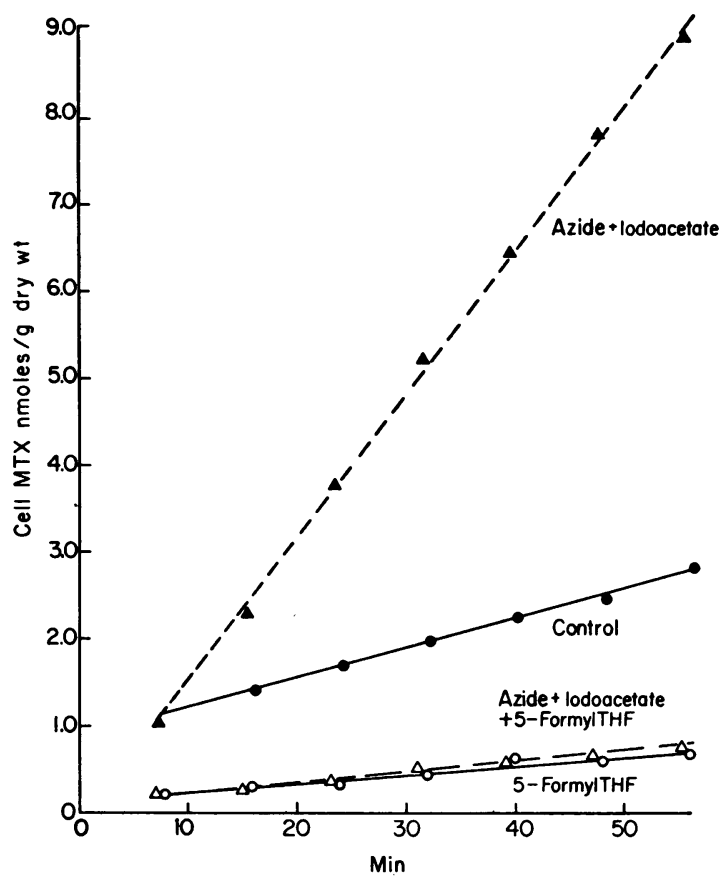

FIgURE 8 The effect of metabolic inhibitors on MTX uptake in the presence and absence of $0.45 \mathrm{~mm} 5$-formylTHF. The cells were exposed to MTX and the inhibitors simultaneously. The azide and iodoacetate levels were $10 \mathrm{~mm}$ and $1 \mathrm{mM}$, respectively. The reticulocyte level was $88 \%$. 
TABLE I

Properties of Erythrocytes Incubated in the Presence or Absence of Metabolic Poisons

\begin{tabular}{|c|c|c|c|c|c|}
\hline & & Dry weight & Extracellular water* & Intracellular water* & (Cl) if \\
\hline Time interval & Condition & Wet weight & Wet weight & Dry weight & (Cl)e \\
\hline $0-20 \mathrm{~min}$ & $\begin{array}{l}\text { Control } \\
\text { Azide-iodoacetate }\end{array}$ & $\begin{array}{l}0.265 \pm 0.010 \S \\
0.258 \pm 0.018\end{array}$ & $\begin{array}{l}0.105 \pm 0.036 \\
0.119 \pm 0.046\end{array}$ & $\begin{array}{l}2.381 \pm 0.142 \\
2.418 \pm 0.150\end{array}$ & $\begin{array}{l}0.695 \pm 0.038 \\
0.703 \pm 0.054\end{array}$ \\
\hline $20-40 \mathrm{~min}$ & $\begin{array}{l}\text { Control } \\
\text { Azide-iodoacetate }\end{array}$ & $\begin{array}{l}0.260 \pm 0.012 \\
0.252 \pm 0.016\end{array}$ & $\begin{array}{l}0.102 \pm 0.036 \| \\
0.135 \pm 0.052\end{array}$ & $\begin{array}{l}2.460 \pm 0.154 \\
2.444 \pm 0.240\end{array}$ & $\begin{array}{l}0.765 \pm 0.056 \\
0.771 \pm 0.046\end{array}$ \\
\hline $40-60 \mathrm{~min}$ & $\begin{array}{l}\text { Control } \\
\text { Azide-iodoacetate }\end{array}$ & $\begin{array}{l}0.253 \pm 0.016 \\
0.259 \pm 0.018\end{array}$ & $\begin{array}{l}0.119 \pm 0.036 \\
0.133 \pm 0.036\end{array}$ & $\begin{array}{l}2.529 \pm 0.190 \\
2.382 \pm 0.202\end{array}$ & $\begin{array}{l}0.801 \pm 0.040 \\
0.755 \pm 0.028\end{array}$ \\
\hline
\end{tabular}

* The extracellular water is determined from the inulin space.

$\ddagger(\mathrm{Cl}) \mathrm{i} /(\mathrm{Cl})$ e refers to the ratio of the concentration of chloride in the intracellular to extracellular water.

$\S$ Values are expressed as the average \pm SD of 8-13 measurements in five separate experiments obtained over the indicated time interval.

$\|$ The difference between control and azide-iodoacetate is not significant at $(P>0.2)$; all other data pairs are not significantly different at $(P>0.5)$.

membrane (Fig. 9). Hence, MTX uptake during the period of observation is downhill into the cell, and nonspecific damage to the cell membrane by the metabolic poisons could lead to an increase in the permeability to MTX by passive diffusion. However, this is excluded by the following observations: $(a)$ the unaltered inulin space (Table I) suggests that membrane integrity is sustained in the presence of metabolic poisons, and $(b)$ the stimulation of MTX uptake by azide and iodoacetate is completely abolished by the addition of excess 5-formylTHF to the extracellular compartment as indicated by the open points in Fig. 8.

The effect of structurally unrelated cations and anions on MTX uptake. When extracellular sodium is replaced by either lithium or potassium, the second component uptake velocity is unchanged. However, replacement of extracellular chloride with inorganic or organic anions leads to a marked inhibition of MTX uptake, while replacement of both sodium and chloride by nonelectrolytes leads to an enhanced MTX uptake (Table II).

\section{DISCUSSION}

Although many of the characteristics of MTX uptake in rabbit erythrocytes are similar to those described

\footnotetext{
${ }^{3}$ From the data of Table $I$, the membrane potential is estimated at $6.65 \mathrm{mv}$ from the Nernst equation (11), based on a chloride distribution ratio of 0.76 after a $20-40 \mathrm{~min}$ incubation. Assuming MTX to be a bivalent anion, the expected passive distribution for MTX at this transmembrane potential difference would be an intracellular to extracellular concentration ratio of 0.59 , or an intracellular concentration of $8.85 \mu \mathrm{M}$ when the extracellular level is $15 \mu \mathrm{M}$, as in the azide-iodoacetate-treated cells of Fig. 9. Hence, the actual free intracellular MTX level of $1.85 \mu \mathrm{M}$ achieved after a 40 min incubation in Fig. 9 is only $20 \%$ of the expected level for a passive system.
}

for tumor cells, some significant differences are observed. In L1210 leukemia cells, under usual conditions, intracellular MTX appears to be distributed in a single compartment, both free (osmotically active) and bound to the enzyme dihydrofolate reductase. During uptake of MTX and before saturation of these binding sites, MTX which enters the cells is rapidly bound, free intracellular MTX is not present, uptake is constant with time and represents a unidirectional flux. After saturation of the binding sites, free MTX accumulates, a unidirectional efflux component appears, and the net rate of uptake falls until a steady state is reached (1). In contrast, the time-course of MTX uptake into reticulocytes is characterized by two uptake components, a

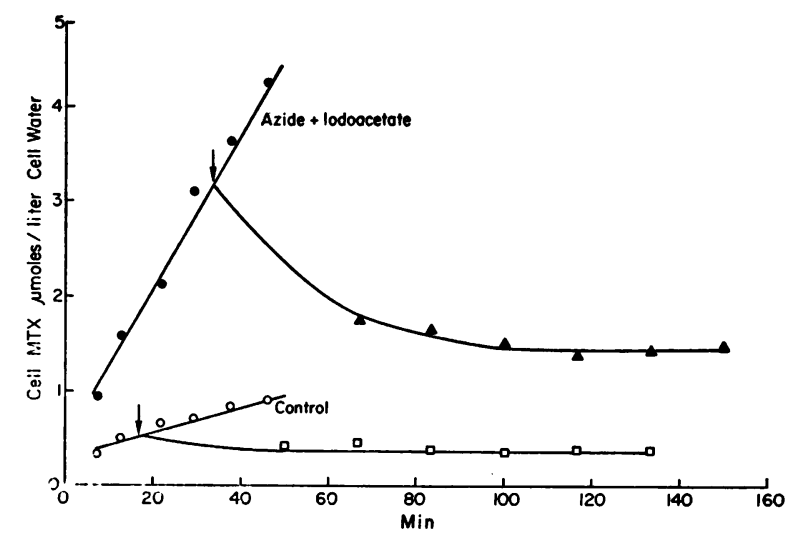

FIGURE 9 The effect of metabolic inhibitors on MTX uptake and exchangeability. Cells were incubated for $10 \mathrm{~min}$ under control conditions or in the presence of $10 \mathrm{~mm}$ azide and $1 \mathrm{~mm}$ iodoacetate. After this, MTX was added to achieve an extracellular level of $15 \mu \mathrm{M}$. At the arrow, portions of the cell suspensions were removed, separated by centrifugation, and resuspended into a large volume of MTX-free buffer at $37^{\circ} \mathrm{C}$. The reticulocyte level was $90 \%$. 
TABLE II

The Effect of Isosmotic Replacement of $\mathrm{NaCl}$ by Various Anions and Cations on the Second Component Uptake Velocity for $M T X^{*}$

\begin{tabular}{|c|c|c|c|}
\hline & Reticulocytes & Rate \pm SD & Control \\
\hline & $\%$ & $\begin{array}{c}\text { nmoles } / \text { min } \\
\text { per } g \text { dry } \\
\text { wt } \times 10^{-2}\end{array}$ & $\%$ \\
\hline \multicolumn{4}{|l|}{$\mathrm{Na}^{+}$replacement: } \\
\hline $\mathrm{NaCl}(135 \mathrm{~mm})$ & & $8.00 \pm 0.48$ & 100 \\
\hline $\mathrm{KCl} \quad(135 \mathrm{~mm})$ & 60 & $8.01 \pm 0.60$ & $100 \ddagger$ \\
\hline $\mathrm{LiCl}(135 \mathrm{~mm})$ & & $8.50 \pm 0.48$ & $106 \ddagger$ \\
\hline \multicolumn{4}{|l|}{$\mathrm{Cl}^{-}$replacement: } \\
\hline Control & & $12.32 \pm 0.96$ & 100 \\
\hline $\mathrm{PO}_{4}(24 \mathrm{~mm})$ & 90 & $10.43 \pm 0.60$ & 85 \\
\hline $\mathrm{NO}_{3}(135 \mathrm{~mm})$ & & $6.01 \pm 0.12$ & 49 \\
\hline Glucose-6- $\mathrm{PO}_{4}(100 \mathrm{~mm})$ & & $6.25 \pm 0.24$ & 51 \\
\hline \multicolumn{4}{|l|}{$\mathrm{Na}^{+}$and $\mathrm{Cl}^{-}$replacement: } \\
\hline Control & & $5.49 \pm 0.42$ & 100 \\
\hline$\frac{1}{2}$ Sucrose $170 \mathrm{~mm}$ ) & 40 & $9.36 \pm 0.42$ & 170 \\
\hline $\left.\begin{array}{ll}\text { Sucrose } & (112 \mathrm{~mm}) \\
\text { Urea } & (129 \mathrm{~mm})\end{array}\right\}$ & & $15.66 \pm 0.48$ & 285 \\
\hline
\end{tabular}

* The extracellular MTX concentration was $0.5 \mu \mathrm{M}$. $\ddagger P>0.5$.

rapid initial uptake followed by a slower uptake at an essentially constant rate and the cells do not achieve a steady state over the usual interval of observation. The kinetics of this process can be interpreted as representing uptake of MTX into either one or two membrane-defined intracellular compartments, both contiguous with the extracellular compartment: (a) In a two-compartment analysis, the first uptake component would represent rapid equilibration of MTX into a small compartment, its size estimated by the interrupted lines in Figs. 1 and 2. The small quantity of exchangeable MTX observed on efflux studies would be related to this compartment (Fig. 2), and since this represents only one-half the ordinate intercept, an additional bound fraction of MTX within this compartment would be required to account for the difference. The second uptake component would reflect a slow uptake into the major intracellular compartment with subsequent binding-presumably to dihydrofolate reductase. The linearity of this component and the absence of exchangeable MTX in this compartment would suggest that it represents a unidirectional flux. (b) In a single-compartment analysis the deviation from initial rates would be related to a rapid buildup of a back-flux component early in the uptake process. Such a mechanism was proposed to explain the timecourse of folic acid uptake in L1210 leukemia cells (2), and is compatible with an energy-dependent exit mechanism (see below) (3). However, folic acid is rapidly metabolized, neither it nor its metabolites are tightly bound within the cell, and these compounds leave the cell at a rate far greater than the net uptake velocity (2). On the other hand, MTX is not metabolized by the erythrocyte, most of the intracellular MTX is tightly bound, and only a small quantity is free to leave the cell under usual conditions. The apparent high affinity of the intracellular binding sites for MTX, which probably represent dihydrofolate reductase (12), make it unlikely that appreciable amounts of free MTX could accumulate within the intracellular water of a compartment in which these binding sites were still available. Hence, the exchangeable MTX which is present within these cells must be in a distinct membrane-defined compartment. The absence of free intracellular MTX within the major compartment would preclude the presence of an efflux component so that the fall in initial rates could not be due to a back-flux of MTX. Thus, although the data are not conclusive, the results favor the two-compartment analysis. The origin of the smaller compartment in this analysis is not clear. It does not appear to be due to uptake into platelet or leukocyte contaminants.

The second component of MTX uptake represents transport into reticulocytes. This component is proportional to the per cent reticulocytes and disappears as the reticulocyte level approaches zero. This loss of folate transport capacity with maturation of the reticulocyte parallels regression of folate-dependent metabolic activity. This is consistent with other reports that cellular folate content as well as uptake of folic acid is greater in reticulocytes than mature erythrocytes (13). A further relationship between cellular requirements for folate coenzymes and the transport mechanism is suggested by higher rates of folate uptake in proliferating tissues, such as bone marrow (14) and tumor cells (5), as compared to reticulocytes, as well as the observation that folic acid uptake is increased in phytohemagglutinin-stimulated lymphocytes (15). Regression of transport systems with cell maturation is not unique for the folates, but has been observed also for amino acids (16).

The properties of MTX transport in reticulocytes are indicative of a carrier-mediated process (18). Compatible with this are the following: (a) temperature sensitivity of the second uptake component is high with a $Q_{10}$ of 4 ; (b) as the extracellular MTX level is raised, the second component uptake rate (which probably represents a unidirectional flux into the major intracellular compartment) deviates from a first order process and approximates Michaelis-Menten kinetics; (c) uptake of MTX is inhibited by the extracellular presence of either folic acid or 5-formylTHF. Further, 
uptake of MTX is enhanced in cells preincubated with 5-formylTHF, a manifestation of heteroexchange diffusion. These studies do not clarify whether heteroexchange occurs between MTX and 5-formylTHF or between MTX and a metabolite of 5-formylTHF since this folate may be metabolized by these cells. However, whatever the exchanging folate(s), the demonstration of heteroexchange diffusion is firm evidence for a carrier mechanism and indicates, in addition, that the exchanging compounds share, at least in part, the same carrier.

The interpretation of the mechanism by which uptake stimulation for MTX occurs during heteroexchange depends upon the compartmental analysis of this system. In the two-compartment formulation, enhanced uptake of MTX into cells preincubated with 5-formylTHF is due to stimulation of MTX inffux into the major intracellular compartment. This effect is related to the concept that the rate-limiting step in this carrier system is the rate of translocation of free carrier as it moves from the inner to outer boundary of the cell membrane, while the rate of translocation of the carrier complexed with 5 -formylTHF or another folate is greater than that of carrier alone $(4,5,17)$. The stimulation of the second component influx rate for MTX is transient because the efflux of folate is transient as its intracellular level is dissipated; however, the net increment in the cell MTX level is sustained because excess MTX taken up by the cells is bound within the major intracellular compartment. Heteroexchange cannot be explained by increased MTX uptake into the smaller intracellular compartment since free intracellular MTX in this compartment is at equilibrium with extracellular MTX, and changes in the free intracellular level during heteroexchange must be transient. If, as is less likely, the one-compartment analysis pertains, enhanced uptake of MTX during heteroexchange would be due to inhibition of MTX back-flux as folate competitively inhibits MTX efflux as it reacts with carrier at the inner cell membrane and leaves the cell (countertransport) (18).

Previous studies with tumor cells demonstrated that although the folate carrier system has a low affinity for folic acid and a high affinity for its tetrahydrofolate derivatives, this is nonetheless the major route for folic acid uptake into these cells $(1,2,4,5)$. This paper suggests that a similar relationship pertains to the carrier-mediated transport of folates in rabbit reticulocytes. In view of this and the observation that the major folate in the blood of man and rodents is 5methyltetrahydrofolate $(19,20)$, it is likely that uptake of the tetrahydrofolate derivatives of folic acid into folate-dependent tissues is several orders of magnitude greater than that of folic acid itself; thus, folic acid can be of little importance in meeting the requirements of folate-dependent tissues.

Folate uptake in tumor cells and reticulocytes is inhibited by a variety of structurally unrelated anions while there is a lack of dependence of the uptake mechanism on extracellular sodium ions $(5,6)$. The stimulation of MTX influx when both sodium and chloride are replaced by nonionic solutes suggests that chloride is itself inhibitory. The possible implications of these findings with respect to the energetics of the MTX carrier system have been discussed (5). Anion inhibition of folate uptake may reduce folate utilization in clinical conditions in which anions accumulate within the blood such as occurs in uremia. Initial studies indicate that folate influx into tumor cells is inhibited by serum from azotemic humans (21). This is currently under further study.

Previous studies suggested the possibility of two modes of energy coupling to the folate transport system in tumor cells to account for the unusual response to metabolic poisons $(2,3)$. One energy input, highly dependent upon endogenous energy metabolism, may be capable of producing an uphill flow of folate out of the cell while another energy input, less dependent upon minute to minute energy metabolism, may produce an uphill flow of folate into the cell. The steady-state electrochemical-potential difference for folate across the cell membrane would then be determined by the net effect of these opposing processes. In the presence of metabolic poisons, the former energy input is blocked while the latter persists, leading to an augmented uphill flow of folate into the cell as observed in tumor cells (3). Although changes in steady-state energetics for MTX were quantitated in tumor cells, this was not possible in these studies. However, a marked increase in the second component of MTX uptake was observed in reticulocytes upon exposure to metabolic poisons, an observation attributed to the inhibition of an energy-dependent process tending to limit folate uptake in these cells. The possibility that this is due to some nonspecific increase in membrane permeability or a change in the transmembrane potential difference was excluded. The mechanism of uptake stimulation by metabolic poisons again depends upon the analysis of the uptake sequence. If back-flux of MTX is a significant part of the second uptake component then uptake stimulation could be due to an inhibition of this back-flux. If, as more likely, the second component of uptake represents a unidirectional flux, then inhibitors have enhanced this process. Although metabolic poisons enhance the unidirectional influx of MTX into tumor cells, the effect is considerably less than observed here, and the overall increase in net accumulation at the steady state is accompanied by a 
more profound inhibition of the unidirectional efflux process (3).

\section{ACKNOWLEDGMENTS}

The authors wish to thank Dr. Clifford Patlak (Theoretical Statistics and Mathematics Section, National Institute of Mental Health, Bethesda, Md.) for his critical review of this manuscript and Dr. John Bartko of the same institution for his help in the statistical analysis of these studies. The excellent technical assistance of Mrs. Ronald Stanley is acknowledged.

These studies were supported by U. S. Public Health Service Research Grant No. Ca-II725 and an Institutional Grant No. IN 15-L from the American Cancer Society.

\section{REFERENCES}

1. Goldman, I. D., N. S. Lichtenstein, and V. T. Oliverio. 1968. Carrier-mediated transport of the folic acid analog, methotrexate, in the L1210 leukemia cell. J. Biol. Chem. 243 : 5007.

2. Lichtenstein, N. S., V. T. Oliverio, and I. D. Goldman. 1969. Characteristics of folic acid transport in the L1210 leukemia cell. Biochim. Biophys. Acta. 193: 456.

3. Goldman, I. D. 1969. Transport energetics of the folic acid analog, methotrexate, in L1210 leukemia cells. $J$. Biol. Chem. 244 : 3779.

4. Goldman, I. D. 1971. A model system for the study of heteroexchange diffusion: methotrexate-folate interactions in L1210 leukemia and Ehrlich ascites tumor cells. Biochim. Biophys. Acta. 233: 624.

5. Goldman, I. D. 1971. The characteristics of the membrane transport of amethopterin and the naturally occurring folates. Ann. N. Y. Acad. Sci. 186: 400.

6. Goldman, I. D. 1971. Evidence for countertransport of organic phosphates and folates in Ehrlich ascites tumor cells. Fed. Proc. 30: 313.

7. Stokstad, E. L. R., and J. Koch. 1967. Folic acid metabolism. Physiol. Rev. 47: 83.

8. Schreiner, G. E. 1950. Determination of inulin by means of resorcinol. Proc. Soc. Exp. Biol. Med. 74: 117.
9. Dennet, C. A., and N. L. Franklin. 1954. Statistical Analysis in Chemistry and the Chemical Industry. John Wiley \& Sons, Inc., New York. Section 7.82.

10. Toesteson, D. C. 1959. Halide transport in red blood cells. Acta Physiol. Scand. 46: 19.

11. Davson, H. 1964. A Textbook of General Physiology. Little, Brown and Company, Boston. 3rd edition. Chapter 10.

12. Bertino, J. R., B. Simmons, and D. Donohue. 1964. Levels of dihydrofolate reductase and the formateactivating enzyme activities in guinea pig tissues before and after amethopterin administration. Biochem. Pharmacol. 13 : 225.

13. Izak, G., M. Rachmilewitz, N. Grossowicz, K. Galewski, and Sh. Kraus. 1968. Folate activity in reticulocytes and the incorporation of tritiated pteroylglutamic acid into red cells. Brit. J. Haematol. 14: 447.

14. Corcino, J. J., S. Waxman, and V. Herbert. 1971. Uptake of tritiated folates by human bone marrow cells in vitro. Brit. J. Haematol. 20: 503.

15. Das, K. C., and A. V. Hoffbrand. 1970. Studies of folate uptake by phytohemagglutinin-stimulated lymphocytes. Brit. J. Haematol. 19 : 203.

16. Antonioli, J. A., and H. N. Christensen. 1969. Differences in schedules of regression of transport systems during reticulocyte maturation. J. Biol. Chem. 244: 1505.

17. Heinz, E., and P. M. Walsh. 1958. Exchange diffusion, transport and intracellular level of amino acids in Ehrlich carcinoma cells. J. Biol. Chem. 233: 1488.

18. Wilbrandt, W., and T. Rosenberg. 1961. The concept of carrier transport and its corrollaries in pharmacology. Pharmacol. Rev. 13: 109.

19. Bird, O. D., V. M. McGlohon, and J. W. Vaitkus. 1965. Naturally occurring folates in the blood and liver of the rat. Anal. Biochem. 12: 18.

20. Herbert, V., A. R. Larrabee, and J. Buchanan. 1962. Studies on the identification of a folate compound of human serum. J. Clin. Invest. 41: 1134.

21. Jennette, J. C., and I. D. Goldman. 1972. Evidence for impaired transport of folate into folate-dependent tissues in uremia. Clin. Res. $20: 44$. 